\title{
Experiencing the built environment: strategies to measure objective and subjective qualities of places
}

\author{
Allen Sayegh ${ }^{1}$, Stefano Andreani ${ }^{1,2^{*}} \mathbb{B}$, Chrisoula Kapelonis ${ }^{1}$, Natasha Polozenko $^{1}$ and Stefan Stanojevic ${ }^{1}$
}

\begin{abstract}
Background: This article offers an alternative look at the experiential character of the built environment by combining objective analysis and subjective perception. The aim is to measure and elaborate on quantitative descriptions of 'hidden' urban characteristics, attempting to build correlations between different unseen but detectable qualities of cities.

Methods: The study introduces an applied research method to quantify objective features of the built environment and the related subjective experience, prototyping a mobile phone application that both actively and passively measures urban parameters and human perceptions. To test the validity of the research process, a few experiments were performed in Cambridge, MA mapping out a series of different places.

Results: The implementation of the application data in conjunction with the more passive, objective dataset extracted from complementary sensors, resulted in an alternative understanding of everyday spatial interactions and in a taxonomy of urban conditions - revealing the 'mood' of urban environments.

Conclusions: The combination of objective and subjective datasets can help reveal more comprehensive insights and characters of spaces and places within the city, mediating between technology and the built environment and leveraging emotive perceptions of the urban actors in order to influence and inform design decisions.
\end{abstract}

Keywords: Responsive environments, Urban experience, Objective/subjective data, Hidden parameters

\section{Background}

The built environment is one of the most fascinating yet enigmatic artifacts of the human being. We perceive it as a complex entity resulting from the juxtaposition of spaces, flows, experiences, objects, and events. Each environment has certain qualities, and - even though shared characteristics do exist - those qualities vary from place to place. Although a variety of criteria, parameters, and indicators attempt to capture key figures of city life [1], they are yet far from depicting the more subjective aspects that constitute the experiential character of built environments. And far less is known of the role of new media and digital tools in helping understand and improve the relationship between people and urban contexts.

This article offers an alternative look at the experiential nature of the built environment by combining objective analysis

\footnotetext{
* Correspondence: andreani@gsd.harvard.edu

${ }^{1}$ Harvard University - Graduate School of design, 48 Quincy St., 02138

Cambridge, MA, USA

${ }^{2} 1684$ Massachusetts Ave., 02138 Cambridge, MA, USA
}

and subjective perception. On the one hand, the physical reality is constructed out of an established configuration of elements, matter in space, that can be considered more or less static in a contained timeframe. These elements are tangible, with clear relationships between one another, and can be quantified through different means. On the other hand, the individual - the 'urban actor' - filters this environment with her personal, varying perceptions and relations to the surrounding context in specific moments. This article argues that, by building upon objective layers of data and affording them with the complexity and variation of subjective, personal feedback, it is possible to gain a more holistic, novel understanding of the city, and of our presence within it.

The way in which we receive information and data about our interaction and relation to the built environment is largely fed to us through systematized, sensor based statistics. This information gets translated into discrete, numeric, tangible data, which has often been flattened in order to package it in a more comprehensible, digestible form [2]. 
Although data might be framed technically, economically, ethically, temporally, spatially and philosophically [3], the common sensor-based static methods of data collection leave little room for interpretation, and fail to consider the complexities and variables that may influence the ways in which people perceive their surroundings. In fact, each individual experience, perception, view of places is colored by a personal, subjective interpretation. The presented study addresses this additional layer describing the subjective views and attitudes that could potentially impact on and influence how urban data is collected, interpreted, and used.

Putting the human being at the center and forefront, this article draws from an ongoing research pursued by the Responsive Environments and Artifacts Lab (REAL) at the Harvard Graduate School of Design that investigates the role of new augmenting and responsive technologies in articulating, mapping and exploiting the specificities of places through a multi-sensory approach [4]. The objective is to measure and elaborate on quantitative descriptions of 'hidden' urban characteristics, attempting to build correlations between different unseen but detectable qualities of the built environment. This research has been elaborating alternative methods, hacking existing technologies, and devising new tools to: a. measure and quantify qualities of the built environment; $b$. visualize them and make comparisons; c. extrapolate meaning; $d$. create correlations between those qualities and typologies of built environments.

\section{Theoretical Background}

Over the last few years there has been a growing interest in trying to scientifically analyze, quantity, and predict the dynamics and functioning mechanisms of cities. For instance, in his The New Science of Cities Michael Batty employs complexity theory to create mathematical models of different aspects of urban structures and to develop decision-making tools that aim at predicting interactions and flows in future cities [5]. By the same token, Luis Bettencourt and Geoffrey West apply the principle of "scaling" to find correlations between urban metrics and socio-economic systems, and the size of cities, claiming that the understanding of cities' dynamics, growth and evolution in a scientifically predictable, quantitative way is crucial in city planning [6]. In a way, the promise of big data analytics - widely put forward by smart city models [7] - tends towards the limits of an absolutely objective understanding of how cities work. Through the use of sensors, the aim is to be able to have control over urban systems with a systematic top-down approach [8].

In all these studies the subjective view of the individual is often overlooked, and for all the good reasons. Understanding the behavior of people in relation to the built environment is a challenging task, and going deeper into the experiential realm of each unique individual is basically impossible. Nevertheless, there are a number of investigations that attempt to better define the role that urban morphologies, spatial arrangements, and public places design play in conveying certain perceptions to the human being. Some of those first attempts can be traced back to the 1960s with the Psychogeography movement, defined by Guy Debord as "the study of the precise laws and specific effects of the geographical environment, consciously organized or not, on the emotions and behavior of individuals" [9]. The research conducted by the related Situationist International was indeed looking at the arrangement of the elements of the urban setting in close relation with the sensations they provoke.

Continuing the studies carried out by her mentor William H. Whyte on people/public places interaction [10], Jane Jacobs further explored this sensorial character of the built environment in her The Death and Life of Great American Cities. According to Jacobs, when observing how people interact with places, all the human senses should be taken into account, and not just sight: "While you are looking, you might as well also listen, linger and think about what you see" [11]. All these observations and studies on the impact of the built environment in people's mindset and behavior eventually translated into planning recommendations and design strategies through the work of Jan Gehl [12], among others. Following this line of thought, the experiential character and ambience of places is well articulated by Juhani Pallasmaa's 'sensory architecture,' as a way to encompass in the design of spaces and buildings the acoustic, haptic, aromatic, etc. aspects [13]. He even suggest a definition of 'experiential atmosphere:' [14].

Atmosphere is the overarching perceptual, sensory, and emotive impression of a space, setting, or social situation. It provides the unifying coherence and character for a room, space, place, and landscape, or a social encounter. It is 'the common denominator,' the colouring' or 'the feel' of the experimental situation. Atmosphere is suspended between the object and the subject.

\section{Methods}

This study introduces an applied research method to quantify objective features of the built environment and the related subjective experience. The assumption is that the combination of objective and subjective datasets can help reveal a more comprehensive understanding of spaces and places within the city, perhaps identifying their inner 'character.' There are a number of other projects that share some overlaps with the one presented here. For instance, the 'happy maps' developed by Daniele Quercia offer a tool to automatically suggest routes that are not only short but also emotionally pleasant [15]. Urban data is leveraged also in the work of Marco De Nadai, who developed a computational way using smartphones to test Jane Jacobs' conditions for 


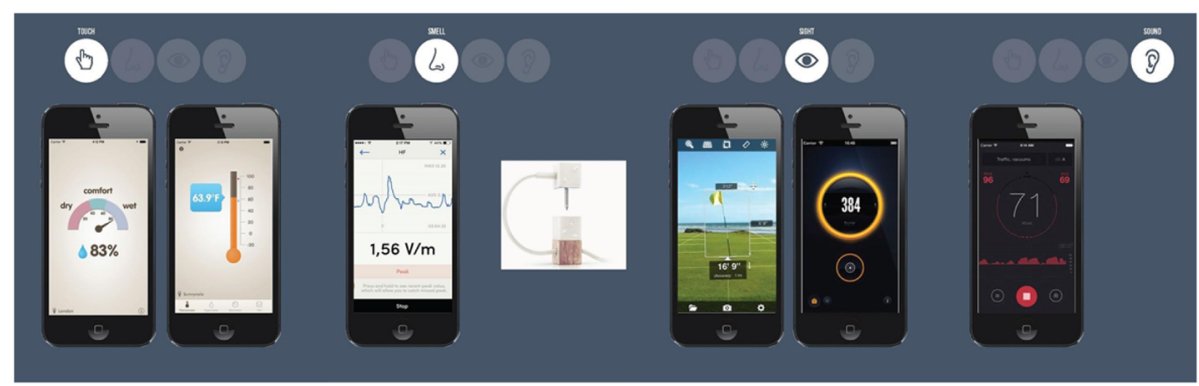

Fig. 1 Smartphone apps that make use of embedded sensors

making cities vibrant and how they relate to the vitality of urban contexts [16]. Christian Nold's Biomapping method then used the galvanic skin response of volunteers as an indicator of emotional arousal in conjunction with their geographical location. The resulting maps visualize points of high and low arousal [17].

In the presented research project the objective data is collected by measuring parameters that can offer an overall representation of the place object of study. In particular, measurements associated with the senses of touch, smell, sight, and sound (including temperature, spatial qualities, brightness, etc.) are performed through smartphone apps that leverage on embedded sensors or add-ons (Fig. 1). For instance, the Thermo-Hygrometer app measures and displays outside temperature, humidity, air pressure and THI of current location [18]; Lapka's sensors quantify to the invisible world of particles, ions, molecules and waves [19]; EasyMeasure uses the height of the camera lens and its tilt angle to calculate the distance to an object and its dimensions [20]; Light Meter is a lux measurement tool for measuring light intensity and luminosity [21]; and $\mathrm{dB}$ Meter measures the sound level in decibel [22]. These parameters and their combination result in a quantitative description of tangible features of the environment.

The more complex subjective experience is instead quantified through two modes of data collection - passive and active (Fig. 2). Passive measurement involves processing existing information that is already being transmitted and collected from personal digital devices. Today's smartphones come with a range of means of data collection, which are commonly utilized by social media, search engines, and apps in order to collect information about the users. This data facilitates the creation of generic profiles that characterize people based on their age, gender, race, socioeconomic background, etc. These platforms also allow for a preliminary characterization of the individual

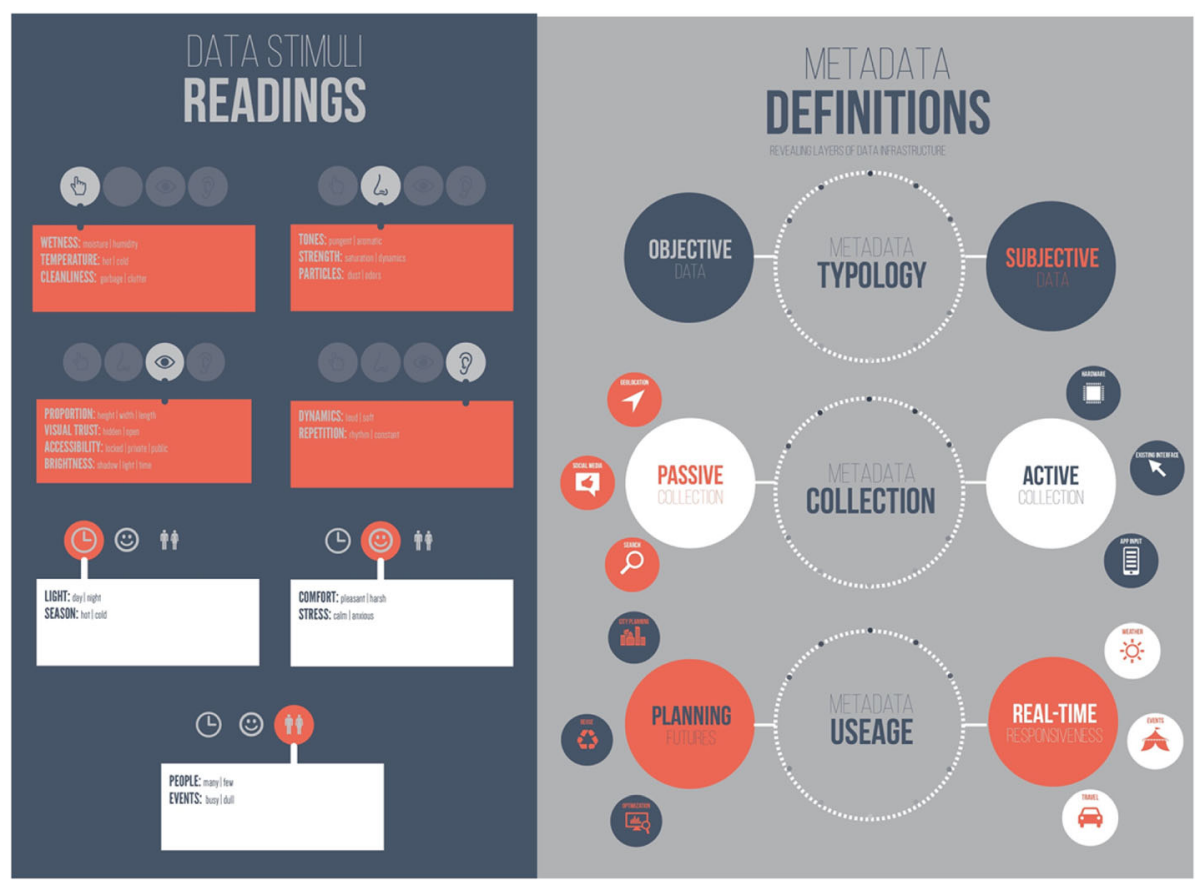

Fig. 2 Definition of 'objective' and 'subjective' parameters of the built environment 


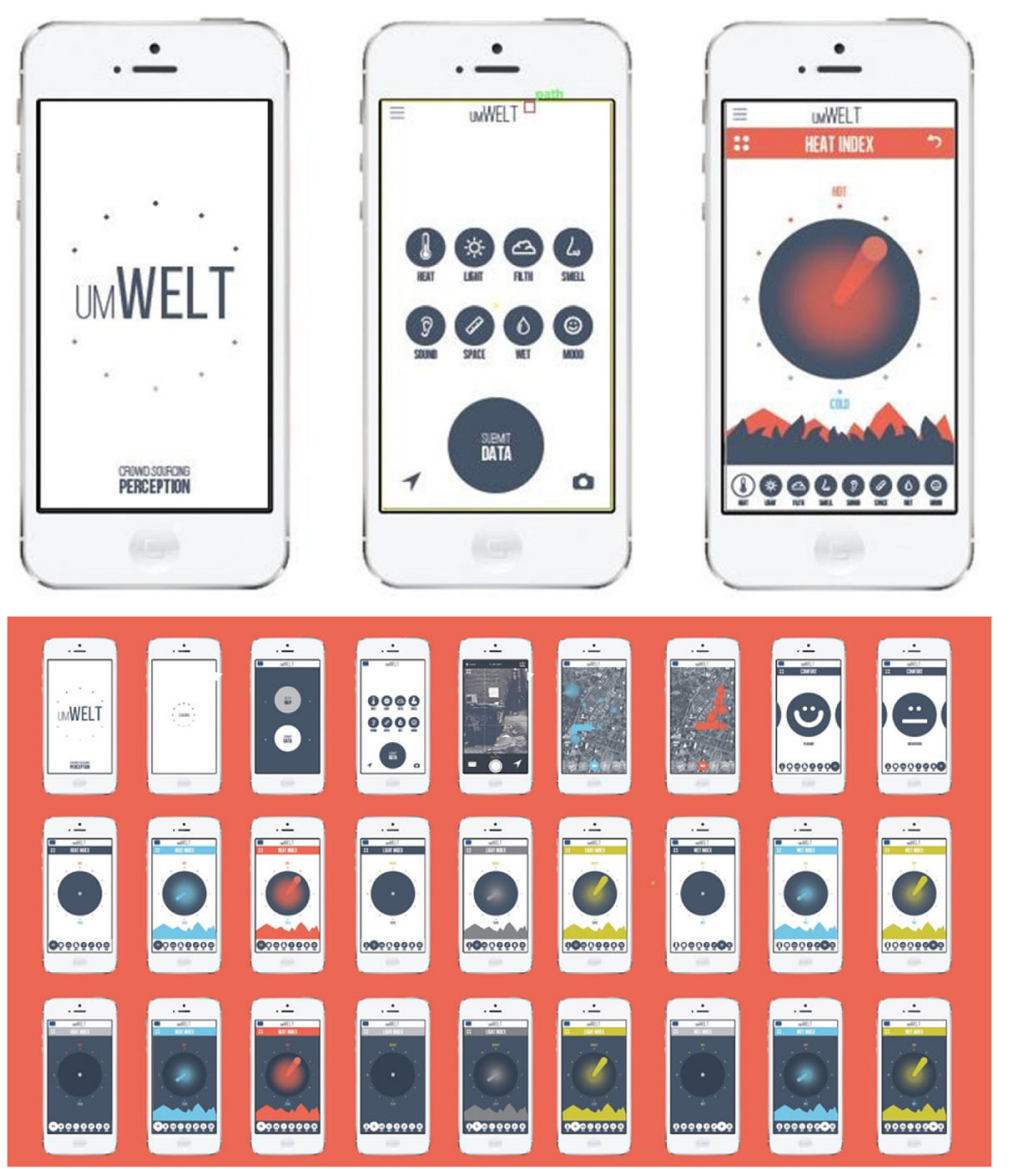

Fig. 3 The UMWELT mobile application prototype

psyche, learning about the user's interests, desires, patterns, and habits. Facebook, for instance, obtains basic information on demographics, as well as a more detailed personal profile which is based on user inputs of status updates, likes, posts, shared links etc. Emoticons allow for a legible expression of emotions, providing Facebook with discrete categorical information on moods and feelings of the individual, as well as of a larger collection of people [23]. Other examples are search engines such as Google, who derives data from search histories, and apps like

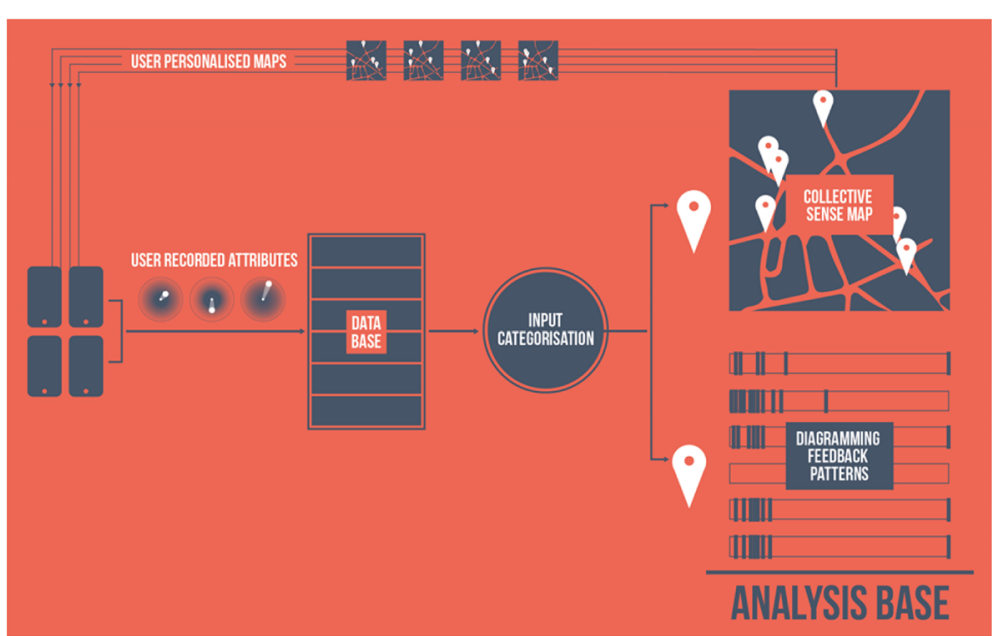

Fig. 4 UMWELT information flow diagram 
Google Maps recognize interests, patterns, and habits in everyday actions, creating personalized digital landscapes [24]. A dialogical relationship exists between the human interaction with the environment and the technology itself, in that Google suggests areas of interest, serving to influence human decision making processes. These modes of data collection describe just some of the possible means of information gathering, facilitating the accumulation of layers of basic subjective data.

This information is successful in allowing for a preliminary overview and understanding of individuals, and the ways in which they use their environment. However this data possesses shortcomings in that it is a simplified view of the human/city relationship. Data becomes more meaningful and substantial with an added layer of active, subjective inputs. One way of obtaining this active subjective data set is through a greater and incentivized engagement of the individual, by means of a smartphone application. Apps are particularly successful in gathering real time information, and allowing for an active engagement and participation, based on the pure fact that smartphones have become an extension of the human and allow for constant input and feedback loops [25].

To that end, the research team designed and prototyped the app "UMWELT" (Fig. 3). It is based on the premise of engaging individual users to input basic descriptions of sensorial perceptions through valuation of the varying intensity at which they experience stimuli, such as sound, light, cleanliness, smell, temperature, wetness, and space. The interface of the app is designed to negotiate through

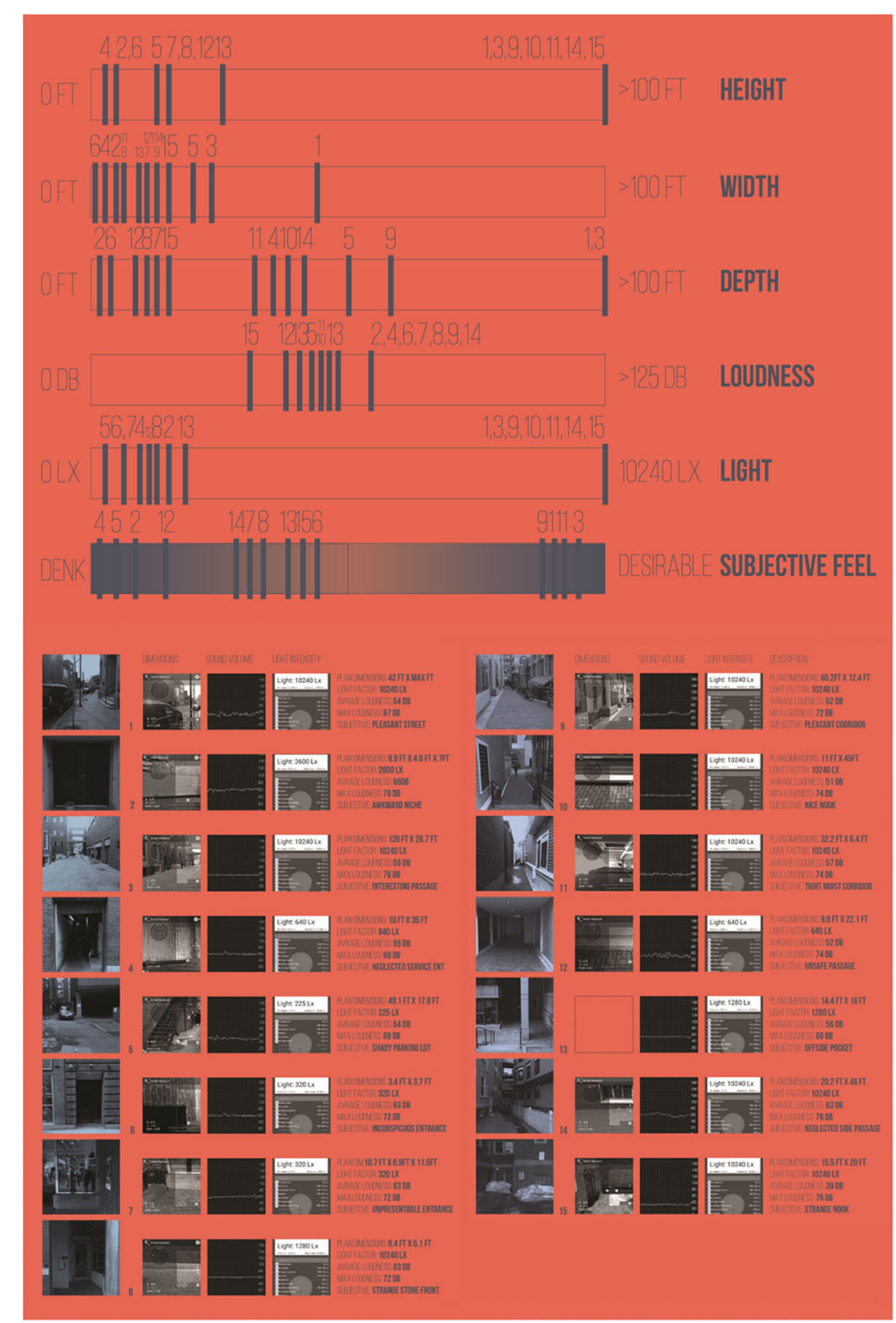

Fig. 5 Objective and subjective data collection in Cambridge, MA 
a gradient of two extremes, allowing for a loose assessment of the stimuli. For each index - such as comfort, light, heat, smell, sound, space, etc. - the user can provide her own response by sliding the picker in the dynamic canvas. The app thus becomes able to understand and translate intuitive experiences into measured information, allowing for a more tangible, quantitative description of personal perceptions of the environment (Fig. 4). An additional form of input involves the logging of a predominant mood of the user, creating a correlation between the experienced phenomena and the emotional response, and facilitating the personalization of an individual cognitive landscape.

\section{Results and discussion}

To test the validity of the research methods and tools, a few experiments were performed in Cambridge, MA mapping out a series of different places. The result is a taxonomy of urban conditions described through both objective and subjective parameters (Figs. 5 and 6). The implementation of the UMWELT data in conjunction with the more passive, objective dataset extracted from complementary sensors, resulted in an alternative understanding of everyday spatial interactions. This novel analysis of the built environment and the ways in which people perceive it allows for new opportunities and potentials to enhance the interactions between the user and the city, through the recommendation and curation of certain experiences - elements and actions that are personally catered to the individual.

In this way it then becomes possible to mediate between technology and built form, establishing a synchronicity between the two - "urbanizing technology," in the words of Saskia Sassen [26] - and fully engaging and utilizing emotive perceptions of the urban actors in order to influence and inform the built environment, and vice versa. The implementation of data, both

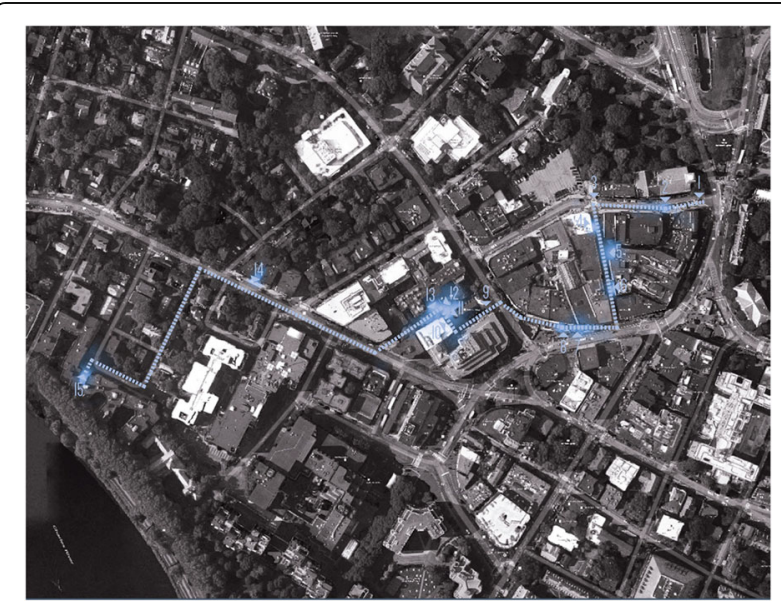

Fig. 6 Map of the field experiments in Cambridge, MA subjective and objective, is in fact crucial to the behavior of the individual whilst navigating the built environment via digital terms. To that end, the data needs not only to be collected, but also put back into the system to benefit and retrofit the behavior of the user through feedback loops [27]. Creating this understanding of the city enables applications in larger scale planning efforts, providing valuable information for the larger intervention decisions by design and planning disciplines. The presented tool might as well be used by citizens who can be exposed to 'hidden' characteristics of places.

\section{Conclusions}

The presented mode of thinking about data allows for a range of interpretations and applications which may serve to enhance or manipulate human interaction and experience within the built environment. These applications are scalar, in that the data can manifest itself into a range of outputs. Real time data may provide the actor with a snapshot overview of the built environment, drawing from an accumulation of certain feelings or perceptions based on the data inputs of numerous other actors. These nodal points, or snapshot into particular moments within the urban form, have the potential to build upon each other as data inputs increase, creating a culmination of data which could then manifest itself into larger networks and have an impact throughout the city. By revealing the 'mood' of urban environments, this data could in fact be used by city planners to better inform programmatic strategies at different levels - from urban acupuncture interventions to larger infrastructural changes.

A work-in-progress application of this research is focused on how people relate to different modes of urban mobility. Through the accumulation of subjective datasets, the objective is to draw a picture of the moods, emotions, and feelings at different points of the commute or trip. The assumption is that in the future machine intelligence will provide personalized routes catered to the desires and preferences of the actor [28], for example, providing routes that are most safe, comfortable, or exciting to the individual. With the emerging of big-data driven connected vehicles and self-driving cars [29], this level of route customization might very well disrupt even conventional infrastructure boundaries.

Authors' contribution

All authors read and approved the final manuscript.

Competing interests

The authors declare that they have no competing interests.

Received: 13 September 2016 Accepted: 17 November 2016 Published online: 12 December 2016

References

1. Tan KG, et al. Ranking the Liveability of the World's Major Cities. World Scientific Publishing Co. 2012. 
2. Gitelman L. "Raw Data" Is an Oxymoron. Cambridge, MA: The Mit Press; 2013.

3. Kitchin R. The Data Revolution: Big Data, Open Data, Data Infrastructures \& Their Consequences. Los Angeles: SAGE Publications; 2014.

4. Responsive Environments and Artifacts Lab. http://research.gsd.harvard.edu/ real/. Accessed 27 July 2016.

5. Batty M. The New Science of Cities. Cambridge, MA: MIT Press; 2013.

6. Bettencourt L, Geoffrey W. A Unified Theory of Urban Living. Nature. 2010; 467(7318):912.

7. Picon A. Smart Cities: A Spatialised Intelligence. Chichester: Wiley; 2015.

8. Townsend AM. Smart Cities: Big Data, Civic Hackers, and the Quest for a New Utopia. New York, NY: W.W. Norton \& Company, Inc.; 2013.

9. Debord G Introduction to a Critique of Urban Geography. In: Knabb K (ed) Situationist International Anthology, Rev. and Expanded edn. Berkeley, CA: Bureau of Public Secrets, 2006, c1955.

10. Whyte WH. c1980) The Social Life of Small Urban Spaces. New York, NY: Project for Public Spaces; 2001.

11. Jacobs J. The Death and Life of Great American Cities. New York, NY: Random House; 1961.

12. Gehl J, Svarre B. How to Study Public Life. Washington, DC: Island Press; 2013.

13. Pallasmaa J. The Eyes of the Skin: Architecture and the Senses. WileyAcademy: Chichester; 2005.

14. Pallasmaa J. Space, Place, and Atmosphere: Peripheral Perception in Existential Experience. In: Borch C, editor. Architectural Atmospheres: On the Experience and Politics of Architecture. Basel: Birkhäuser; 2014.

15. Quercia D, et al. The Shortest Path to Happiness: Recommending Beautiful, Quiet, and Happy Routes in the City. In: Proceedings of the 25th ACM Conference on Hypertext and Social Media, Santiago, Chile, 1-4 September 2014. Association for Computing Machinery; 2014.

16. De Nadai M, et al. The Death and Life of Great Italian Cities: A Mobile Phone Data Perspective. In: Proceedings of the 25th International Conference on World Wide Web, Montréal, 11-15 April 2016. Association for Computing Machinery; 2016

17. Bio Mapping/Emotion Mapping. http://www.biomapping.net. Accessed 27 July 2016

18. Thermo-Hygrometer. http://apps.morethan.net/thermometer/. Accessed 27 July 2016

19. Lapka. https://mylapka.com. Accessed 27 July 2016.

20. Easy Measure. http://www.caramba-apps.com/easymeasure/. Accessed 27 July 2016.

21. Light Meter. http://lightmeterpro.com. Accessed 27 July 2016.

22. dB Meter. http://dbmeterpro.com. Accessed 27 July 2016

23. Boyd D. It's Complicated: The Social Lives of Networked Teens. New Haven: Yale University Press; 2014.

24. Bratton BH. The Stack: On Software and Sovereignty. Cambridge, MA: MIT Press; 2016.

25. Ratti C. The City of Tomorrow: Sensors, Networks, Hackers, and the Future of Urban Life. New Haven: Yale University Press; 2016.

26. Sassen S. "Open Source Urbanism", Domus, 29. 2011. www.domusweb.it/en/ op-ed/2011/06/29/open-source-urbanism.html. Accessed 27 July 2016.

27. Gabrys J. Program Earth: Environmental Sensing Technology and the Making of a Computational Planet. Minneapolis: University of Minnesota Press; 2016.

28. Kelly K. The Inevitable: Understanding the 12 Technological Forces That Will Shape Our Future. New York, NY: Viking; 2016.

29. Knight W. A Simple Way to Hasten the Arrival of Self-Driving Cars, MIT Technology Review. 2016, 20 April 2015, https:/www.technologyreview. com/s/601297/a-simple-way-to-hasten-the-arrival-of-self-driving-cars/\#/set/ id/601313/. Accessed 27 July 2016

\section{Submit your manuscript to a SpringerOpen ${ }^{\circ}$ journal and benefit from:}

- Convenient online submission

- Rigorous peer review

- Immediate publication on acceptance

- Open access: articles freely available online

- High visibility within the field

- Retaining the copyright to your article 